\title{
Myopic Optimization Models for Simulation of Investment Decisions in the Electric Power Sector
}

\author{
Kris Poncelet, Erik Delarue, Daan Six, William D'haeseleer
}

\begin{abstract}
Generation expansion planning models optimize investment and operational decisions over a time horizon of multiple decades, thereby typically assuming perfect foresight (PF). Recently, myopic optimization models, in which the foresight is restricted to a certain period, have been suggested to more realistically simulate the short-sightedness of investment decision makers. The literature has shown that the modeled level of foresight can have a significant impact on the results obtained. However, the literature does not contain an in-depth analysis of the investment decision making process in myopic optimization models. As a result, the implications of using myopic optimization models to simulate the decision making of private agents in liberalized electricity markets are unclear. This paper provides fundamental methodological insights into the decision making in both $\mathrm{PF}$ and myopic optimization models. The projections, at the time the investment decision is made, of the short-run profits that can be obtained by investing in a generation asset are analyzed in this regard. This analysis reveals a major limitation of the decision making process in myopic optimization models, i.e., the approach does not extrapolate trends, in terms of changes in the projected SR profits, expected within the window of foresight to later periods. This leads to decision making which cannot be considered to reflect reality.
\end{abstract}

Index Terms-Power system planning, liberalized electricity markets, investments under uncertainty, myopic foresight

\section{NOMENCLATURE}

\section{A. Abbreviations}

$\begin{array}{ll}C C G T & \text { combined cycle gas turbine } \\ C C S & \text { carbon capture and sequestration } \\ C G E S & \text { computable general equilibrium } \\ G H G & \text { greenhouse gas } \\ M F & \text { myopic foresight } \\ O C G T & \text { open cycle gas turbine } \\ O \& M & \text { operations and maintenance } \\ P C & \text { post combustion capture } \\ P F & \text { perfect foresight } \\ P V & \text { photovoltaic } \\ P W R & \text { pressurized water reactor } \\ S C & \text { super critical } \\ S R & \text { short run } \\ V O M & \text { variable operations and maintenance }\end{array}$

B. Sets
$\mathcal{G}$ (index $g$ )
Set of generation technologies
$\mathcal{G D} \subset \mathcal{G}$
Set of dispatchable generation technologies

K. Poncelet, E. Delarue and W. D'haeseleer are with the Department of Mechanical Engineering, KU Leuven and EnergyVille, Belgium. K. Poncelet holds a PhD grant of the Flemish Institute of Technological Research (VITO)

D. Six is with the Flemisch Institute of Technological Research (VITO) and EnergyVille, Belgium.
$\mathcal{I}$ (index $i$ ) Set of representative days

$\mathcal{T}$ (index $t$ ) Set of time steps within one day

$\mathcal{V}$ (index $v$ ) Set of vintage years

$\mathcal{Y}$ (index $y$ ) Set of milestone years

\section{Parameters}

\begin{tabular}{|c|c|}
\hline$\Delta_{t}$ & Duration of the time interval $[h]$ \\
\hline$C^{F O M}$ & $\begin{array}{l}\text { fixed operations and maintenance cost } \\
{[E U R /(M W . a)]}\end{array}$ \\
\hline$C^{G E N}$ & generation cost $[E U R / M W h]$ \\
\hline$C^{I N V}$ & overnight investment cost $[E U R / M W]$ \\
\hline$d$ & discount rate $[-]$ \\
\hline$D E M$ & electricity demand $[M W]$ \\
\hline$D E M^{P E A K}$ & peak electricity demand $[M W]$ \\
\hline$E_{x}$ & last year of period containing year $\mathrm{x}[a]$ \\
\hline $\mathrm{EOH}$ & last year of considered time horizon $[a]$ \\
\hline$M U^{L T}$ & $\begin{array}{l}\text { cost mark-up factor to account for the lead } \\
\text { time }[-]\end{array}$ \\
\hline $\bar{P}$ & capacity of a single unit $[M W]$ \\
\hline$S_{x}$ & first year of period containing year $\mathrm{x}[a]$ \\
\hline$T L$ & technical lifetime $[a]$ \\
\hline$W_{i}$ & $\begin{array}{l}\text { number of time representative day } \mathrm{i} \text { is re- } \\
\text { peated within one year }[-]\end{array}$ \\
\hline $\bar{u}$ & reference year for cost discounting $[a]$ \\
\hline
\end{tabular}

D. Variables

$\alpha$
$\beta$
$c^{\text {fom }}$
$c^{\text {gen }}$
$c^{\text {inv }}$
$c^{\text {salv }}$
capew
cap new,av
gen
$n^{\text {on }}$
$P^{d c}$
$P^{e l}$

dual variable of the market clearing constraint $[E U R]$ dual variable of the demand for dispatchable capacity constraint $[E U R]$

fixed operations and maintenance cost $[E U R]$

generation cost $[E U R]$

investment cost $[E U R]$

salvage value $[E U R]$

newly installed capacity $[M W]$

available newly installed capacity $[M W]$

generation $[M W]$

number of online units $[-]$

price of dispatchable capacity $[E U R / M W]$

price of electricity $[E U R / M W h]$

\section{INTRODUCTION}

$\mathbf{P}$ ARTIAL equilibrium generation capacity expansion planning models are used frequently to analyze scenarios for the evolution of the electricity system. Typically, investment and operational decisions over a time horizon spanning 
multiple decades are optimized in a single run assuming perfect foresight (PF), see e.g., [1]. Given the highly uncertain character of certain model inputs, such as future fossil fuel prices, demand or policy interactions, the investment decision making in PF models might not be reflective of reality. As stated in [2], decision makers do not have full information regarding future costs, prices and constraints.

Multiple authors have recently proposed using so-called myopic optimization models to account for the limited foresight and the short-term focus of investment decision makers, which should lead to more realistic results [2]-[4]. In such myopic models, perfect information is assumed for a limited number of years, the so-called window of foresight, while no information is assumed to be available outside this period. This leads to a sequential decision making process with a moving window of foresight, meaning that an investment planning is made for the window of foresight which is revised and extended as new information becomes available. However, the investments that have been made by this point can no longer be reversed.

Keppo and Strubegger [2] have shown, using a myopic version of the global energy-system model MESSAGE, that the reduced foresight causes postponement of investments in new technologies leading to higher investment needs in the future and a higher reliance on fossil fuels in the near term. A similar analysis is performed for a computable general equilibrium (CGE) model in [4].

Myopic models can be a valuable complement for PF optimization models. Where PF models can be used to identify optimal transition pathways, myopic model versions could serve to provide more realistic projections of likely scenarios for the evolution of the electricity system (given certain expectations and policies) [5]. Moreover, using both approaches in parallel could facilitate assessing both the effectiveness and efficiency of certain policy instruments. An important advantage is that the ideal and likely scenarios can be generated within a single framework as using a myopic model version requires only minor changes to the model. In contrast, other types of models, such as agent-based models (e.g., [6]) or system-dynamics models (e.g., [7]) can only be employed for generating likely scenarios for the evolution of the electricity system.

Another welcome advantage of myopic model versions is that the shorter time horizon reduces the computational cost. This allows increasing the level of temporal, geographical and/or technical detail, which is shown to be crucial for capturing the challenges related to the integration of intermittent renewables [8], [9], [10]. In this regard, Babrowski et al. [3] propose to use myopic models merely as a means to reduce computational cost.

Despite these apparent opportunities, the literature regarding methodological aspects of using myopic optimization models is scarce and contains a number of gaps. While there is some literature discussing the impact of using a limited window of foresight on the outcome of models, this literature is restricted to global models comprising all energy sectors (e.g., [2], [3]). As such, the term 'decision maker' remains abstract and the underlying implicit assumptions of the decision making process have not been discussed in detail. As a result, the implications of using myopic optimization models to simulate decision-making of private agents in liberalized energy markets are unclear.

The aim of this paper is to provide methodological insights into the opportunities and limitations of myopic optimization models for simulating investment decisions in liberalized and competitive energy markets.

The remainder of this paper is organized as follows. Section II discusses the methodology employed and presents a description of the model used. Subsequently, the data and assumptions are discussed in Section III. Next, the results are discussed in Section IV and finally a conclusion is presented in Section V.

\section{Methodology}

To analyze the impact of the level of foresight on the investment decisions, and hence on the evolution of the electricity generation mix, the results of a model using perfect foresight (PF) are compared to the results of a model using a myopic window of foresight of 10 years (MF10). Both models will be used to generate a single scenario for the evolution of an electricity system inspired by the Belgian case.

In the perfect foresight scenario, investments and operations are optimized in a single optimization covering the time horizon 2020-2075. This time horizon is subdivided into periods of five years. In the MF10 scenario, the foresight is restricted to the next 10 years, again being divided into periods of 5 years. Similar to [2], a moving horizon approach is used to simulate sequential decision making. Every 5 years, a new investment planning is made, allowing previously planned investments to be revised if construction has not yet started. A schematic of both scenarios is presented in Fig. 1.

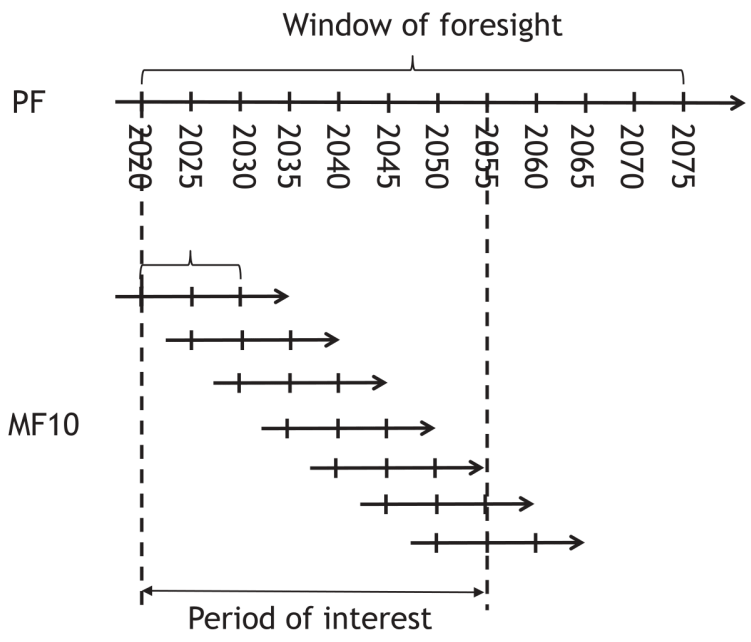

Fig. 1: Schematic of the PF and MF10 scenarios.

The results of PF scenario and the MF10 scenarios are compared in terms of the capacity mix, the generation mix, and the emissions of greenhouse gasses.

To analyze the investment decision making in both scenarios, we take a deeper look into the projected revenues, operational costs and resulting short-run profits of different investments. Assuming little uncertainty on the fixed costs, it is these projections of short-run profits which will be the driver for deciding whether or not to invest. 


\section{A. Model description}

The investment-planning version of the model LUSYM (Leuven University SYstem Model) is used in this paper. This is a linear bottom-up partial equilibrium model of the electric power sector. The objective function is to minimize the total discounted cost related to both investments and operation of generation assets over a time horizon that can be determined freely by the user. Similar to the TIMES model, the time horizon can be divided flexibly into periods of multiple years [11]. Each period is represented by its middle year $y \in \mathcal{Y}$, the so-called milestone year. Discounting of costs occurs to a specific reference year $\bar{y}$ using a discount rate $d$. The symbols used are defined in the Nomenclature section on the first page of this paper.

1) Costs: The costs to be minimized include investment costs, fixed operations and maintenance (O\&M) costs and generation costs (comprising fuel costs, costs related to the emission of greenhouse gasses and variable O\&M costs) as specified in Equation 1. All costs are transformed into an equivalent cost to be paid in the milestone year, which are in turn discounted to the year $\bar{y}$ (Equation 1).

$$
\begin{aligned}
& \min O b j=\sum_{y} \frac{1}{(1+d)^{(y-\bar{y})}} *\left(\sum _ { g , y } \left(c_{g, y}^{i n v}+c_{g, y}^{f o m}\right.\right. \\
& \left.\left.-c_{g, y}^{s a l v}\right)+\sum_{g, v, y} c_{g, v, y}^{g e n}\right) \\
& c_{g, y}^{i n v}=\sum_{v: v=y} c a p_{g, v}^{n e w} * C_{g, v}^{I N V} * M U_{g, v}^{L T} *(1+d)^{\left(y-S_{v}\right)} \\
& c_{g, y}^{s a l v}=c_{g, y}^{i n v} * \sum_{v: v=y} * \max \left\{\begin{array}{l}
\frac{1-(1+d)^{S_{v}+T L_{g, v}-E O H-1}}{1-(1+d)^{T L_{g, v}}} \\
0
\end{array}\right.
\end{aligned}
$$

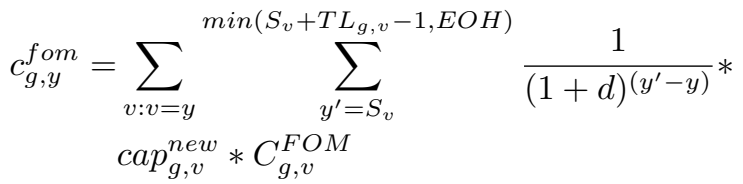

$$
\begin{aligned}
& c_{g, v, y}^{g e n}=\sum_{y^{\prime}=S_{y}}^{E_{y}}\left(\frac { 1 } { ( 1 + d ) ^ { ( y ^ { \prime } - y ) } } * \sum _ { i } \left(W_{i} *\right.\right. \\
& \left.\left.\sum_{t}\left(g^{e n} n_{g, v, y, i, t} * \Delta_{t} * C_{g, v, y}^{G E N}\right)\right)\right)
\end{aligned}
$$

The techno-economic characteristics of the different assets are dependent on the period when the asset becomes operational, i.e., the so-called vintage year $v$. The cost related to investment in an asset of technology $g$ that becomes available at the start of the period containing milestone year $y$ (i.e., the asset has vintage year $v=y$ ) is specified in Equation 2. In this equation, $M U_{g, v}^{L T}$ is a cost markup with respect to the overnight investment cost $C_{g, v}^{I N V}$ to account for interests to be paid during the lead time of the construction. In addition, the last factor in Equation 2 accounts for the fact that the resulting lump-sum investment cost occurs at the start of the period rather than in the milestone year. Assets that have not reached the end of their assumed technical lifetime at the end of the model horizon (EOH) are valorized, i.e., a negative term enters in the objective function. Valorizing remaining assets is crucial for every dynamic investment model to avoid penalizing capital intensive assets towards the end of the model horizon [12]. For myopic models, in which the modeled time horizon, being equal to the window of foresight, is typically shorter than the life time of certain generation assets, this valorization of capacity after the end of the model horizon becomes even more important. Quantification of the so-called salvage value of generation assets is typically based on two assumptions: (i) the total discounted value of an asset is equal to its total discounted investment cost, and (ii) the value of an asset is distributed homogenously over its assumed technical lifetime. Under these assumptions, the salvage value of a remaining asset is as presented in Equation 3. Note that the fraction of the investment cost that is recovered at the end of the optimization horizon is known prior to the optimization and can therefore be entered into the model directly, without requiring using the non-convex max function.

Besides investment costs, fixed O\&M costs need to be paid during every year of the modeled horizon during which the asset is available (Equation 4).

Operations, and hence generation costs, are assumed to be equal in all years within a period. Intra-annual variations in demand and supply are represented using 8 representative historical days $i \in \mathcal{I}$, which are selected following the methodology presented in [13]. Each representative day is repeated a number of times $W_{i}$, the operational costs during each day are scaled accordingly (Equation 5). Moreover, every representative day is disaggregated further into hourly time intervals $t \in \mathcal{T}$.

2) System constraints: The most important system constraint is that supply and demand of electricity must be in balance in every time step (Equation 6). In addition, there is a demand for dispatchable capacity exceeding the yearly peak load by $5 \%$ (Equation 7). The duals $\alpha_{y, i, t}$ and $\beta_{y}$ of these system constraints will be used to determine the obtained revenues for each asset. This is discussed in detail in Section II-B.

$$
\begin{gathered}
\sum_{g, v} g e n_{g, v, y, i, t}=D E M_{y, i, t} \perp \quad \alpha_{y, i, t} \Omega \\
\sum_{g \in \mathcal{G D}, v}{ } a p_{g, v, y}^{n e w, a v} \geq 1.05 * D E M_{y}^{P E A K} \stackrel{\beta_{y}}{ }
\end{gathered}
$$

3) Technological constraints: The generation of each asset is restricted by a number of operational constraints. First and foremost, the generation is restricted to its installed capacity (Equation 9-10). To this end, the available capacity in a period $y$ of an asset of technology $g$ that has become available in the period containing $v$ needs to be determined (Equation 8). Note again that the fraction of the initial installed capacity that is available in every period can be determined prior to the optimization. To approximate detailed techno-economic constraints, such as ramping-rate restrictions, minimum up and down times and start-up costs, a linearized clustered unitcommitment formulation is used similar as in [14]. A full 
description of these techno-economic constraints can be found in [15]. Crucial in this formulation is that there is a distinction between the number of units online $n_{g, v, y, i, t}^{o n}$ and the actual generation level $g e n_{g, v, y, i, t}$.

$$
\operatorname{cap}_{g, v, y}^{n e w, a v}=\operatorname{cap}_{g, v}^{n e w} * \begin{cases}0, & \text { if } y<v \\ 1, & \text { if } S_{v}+T L_{g, v} \geq E_{y} . \\ \frac{S_{v}+T L_{g, v}-S_{y}}{E_{y}-S_{y}+1}, & \text { else. }\end{cases}
$$

$$
\begin{aligned}
& n_{g, v, y, i, t}^{o n} \leq \frac{\operatorname{cap}_{g, v, y}^{n e w, a v}}{\overline{P_{g, v}}} \\
& \operatorname{gen}_{g, v, y, i, t} \leq n_{g, v, y, i, t}^{o n} * \overline{P_{g, v}}
\end{aligned}
$$

\section{B. Determining short-run profits}

To gain insights into the investment-decision-making process in both the perfect foresight and the myopic model, the projected short-run (SR) profits of different assets will be analyzed at the time of the decision making. SR profits are defined here as the revenues subtracted by the operational costs (Equation 11), i.e., the infra-marginal rent. These SR profits can be considered as the value of having an asset available in a certain year. In order for the investment to be profitable, the present value of the short-run profits should be higher than the present value of the annualized fixed costs (including both investment and fixed O\&M costs). Therefore, the investment decision making can be analyzed by comparing the projected SR profits to the annualized fixed costs.

To determine the revenues, the price for electricity and dispatchable capacity is derived from the marginal values of the market clearing constraint (Equation 6) and the demand for dispatchable capacity (Equation 7) respectively (see Equations 12-13). In these equations, the factor $(1+d)^{(y-\bar{y})}$ is applied to convert prices to the year in which they occur. Moreover, the factor $\sum_{y^{\prime}=S_{y}}^{E_{y}} \frac{1}{(1+d)^{\left(y^{\prime}-y\right)}}$ is used to account for the fact that multi-year periods are used, whereas we are interested in the prices in a single year.

$$
\begin{gathered}
S R \_ \text {Profits } s_{g, v, y}=\operatorname{cap}_{g, v, y}^{n e w, a v} * P_{y}^{d c} \\
+\sum_{i, t}\left(\left(P_{y, i, t}^{e l}-C_{g, v, y}^{G E N}\right) * g e n_{g, v, y, i, t} * W_{i} * \Delta_{t}\right) \\
P_{y, i, t}^{e l}=\frac{\alpha_{y, i, t} *(1+d)^{y-\bar{y}}}{\sum_{y^{\prime}=S_{y}}^{E_{y}} \frac{1}{(1+d)^{\left(y^{\prime}-y\right)}} * W_{i} * \Delta_{t}} \\
P_{y}^{d c}=\frac{\beta_{y} *(1+d)^{y-\bar{y}}}{\sum_{y^{\prime}=S_{y}}^{E_{y}} \frac{1}{(1+d)^{\left(y^{\prime}-y\right)}}}
\end{gathered}
$$

\section{DATA AND ASSUMPTIONS}

The existing capacity in Belgium is used as a starting point of the optimization. Data on the current capacity is made available by the Belgian TSO Elia [16]. The planned nuclear phase-out is implemented following current legislation leading to a gradual phase-out between 2022 and $2026^{1}$. In addition, the lifetime of existing fossil-fueled plants and renewable generation assets is taken into account for determining the retirement of existing capacity. Data regarding the economic and and technical characteristics of different technologies are taken from [17] and [18] respectively. The data used here are presented in Tables I-II in Appendix A.

The Belgian electricity demand profile from the year 2014, as provided by the Belgian TSO [16], is used as a starting point. An annual growth of this demand with $1 \%$ per year is assumed throughout the modeled time horizon. Onshore wind and solar PV feed-in profiles are also taken from the Belgian TSO [16].

The carbon price is assumed to increase linearly from 10 EUR/ton in 2020 to $40 \mathrm{EUR} /$ ton in 2030. Afterwards, a linear increase of $20 \mathrm{EUR} /$ ton per decade is assumed.

In the simplified case study, Belgium is assumed to be an island, and grid-related constraints within the country are not considered.

\section{RESUlts}

\section{A. Impact on model results}

The evolution of installed capacities in the PF and MF10 scenario are presented in Figures $2 \mathrm{a}$ and $3 \mathrm{a}$ respectively. Around 2020-2025, there is a strong need for additional capacity as existing nuclear plants reach the end of their legally imposed exploitation period. Significant differences between the PF and MF10 scenarios can be observed with respect to how this nuclear capacity is replaced. In the PF scenario, the replacement occurs predominantly by an expansion of the CCGT and OCGT capacity. In contrast, in the MF10 scenario, there is a massive development of new supercritical coal-fired generation capacity. Also, towards the end of the considered time horizon, interesting differences occur in terms of investments in carbon capture and sequestration (CCS) technologies. While in both the PF and MF10 scenario, there are investments in coal-fired as well as gas-fired CCS plants, there are differences in both the amount of capacity invested in and the timing of the investments. In the PF scenario, CCS investments start with and are dominated by postcombustion (PC) capture CCGTs. In contrast, in the MF10 scenario, mainly PC supercritical (SC) coal-fired power plants are invested in.

The annual electricity generation by different technologies in both the PF and MF10 scenario are presented in Figures $2 \mathrm{~b}$ and $3 \mathrm{~b}$. Following the differences in installed capacity, main differences in terms of electric energy generation can be observed in the amount of coal-fired generation in the first half of the considered time horizon as well as the type of CCS generation more towards the end of the considered time horizon. The implications of this in terms of annual greenhouse gas $(\mathrm{GHG})$ emissions in both scenarios are presented in Figure

\footnotetext{
${ }^{1}$ The operating license of the units Doel 3 and Tihange 2 respectively expires at the end of 2022 and early 2023. Early 2025, the operating license of Doel 1 expires, while at the end of 2025, the license of Doel 2 expires. Finally, throughout 2026, the licenses of Doel 4, Tihange 1 and Tihange 3 expire.
} 
PF

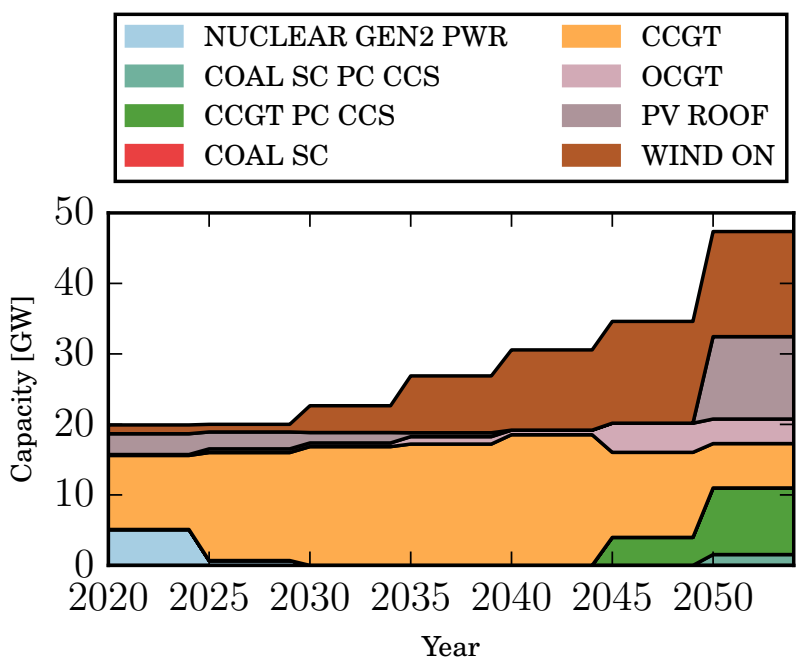

(a) Installed capacity

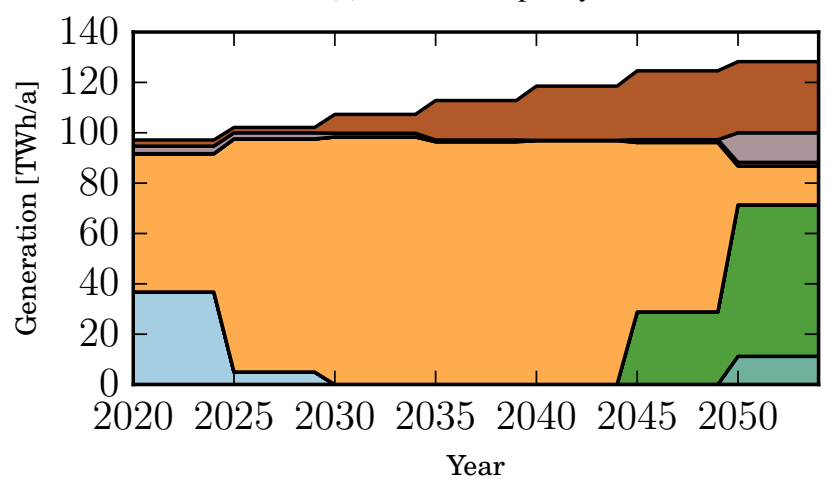

(b) Annual electric energy generation

Fig. 2: Installed capacity and annual electric energy generation in the PF scenario.

4. Over the considered time horizon, GHG emissions in the MF10 scenario are almost $35 \%$ higher than in the PF scenario.

At this point, it is important to stress that the aim of this paper is not to generate detailed scenarios for the evolution of the Belgian electricity system. Nor is it to quantify the impact of the level of foresight. Rather, the aim is to provide methodological insights into the implicit investment-decisionmaking process in perfect foresight models and their myopic counterpart. In this regard, the case presented here is merely used as a means to highlight the investment decision making in both approaches.

\section{B. Investment decision making}

In this section, the investment decision making in both models is analyzed in more detail. As discussed in Section II-B, we do so by comparing the projected short-run profits to the annualized fixed costs of the assets.

1) Perfect foresight: Figure 5 displays the evolution of the SR profits of all CCGT assets as a function of time and the year the asset has become operational. In addition, the annualized fixed costs are displayed. As is illustrated in this
MF10

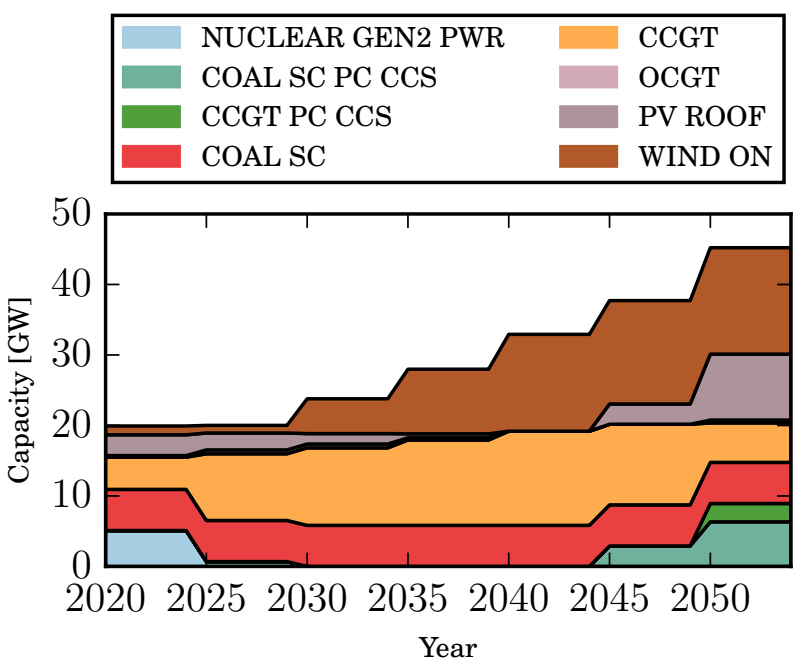

(a) Installed capacity

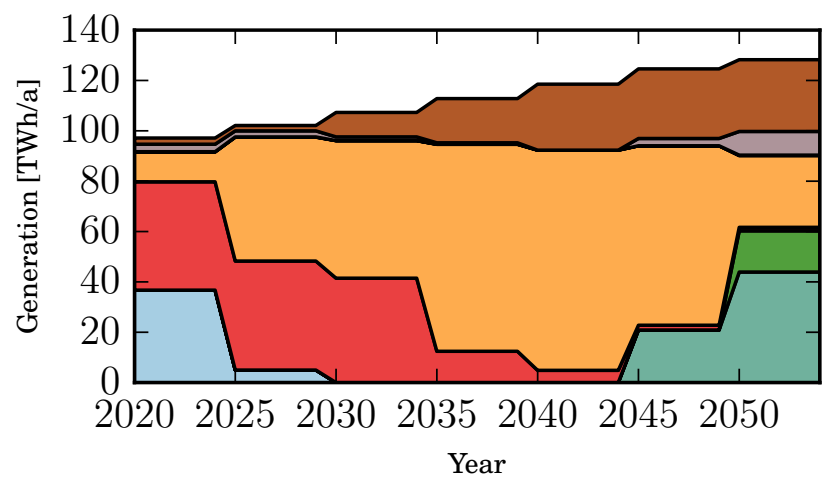

(b) Annual electric energy generation

Fig. 3: Installed capacity and annual electric energy generation in the MF10 scenario.

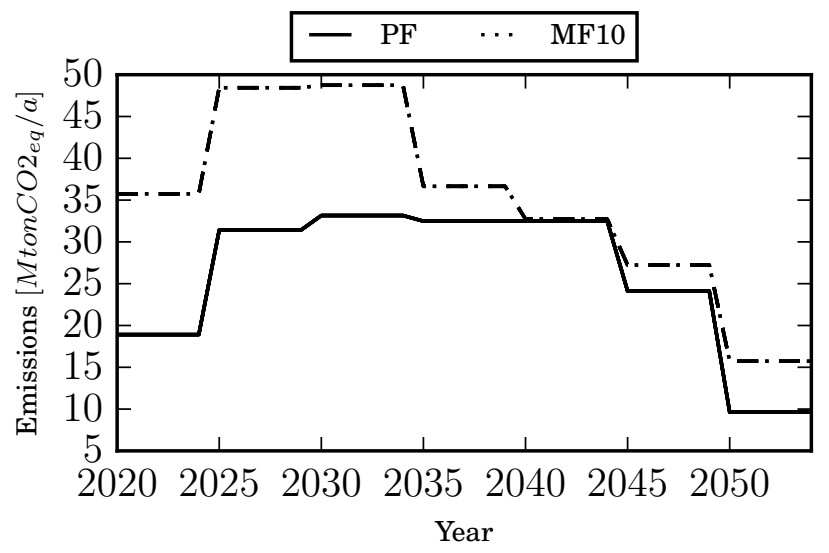

Fig. 4: Evolution of annual GHG emissions in the PF and MF10 scenarios.

figure, the amount of short-run profit that can be obtained with an asset can vary strongly over its lifetime.

In some cases, the trend can be explained relatively easily. One such example is the continuously decreasing value of 


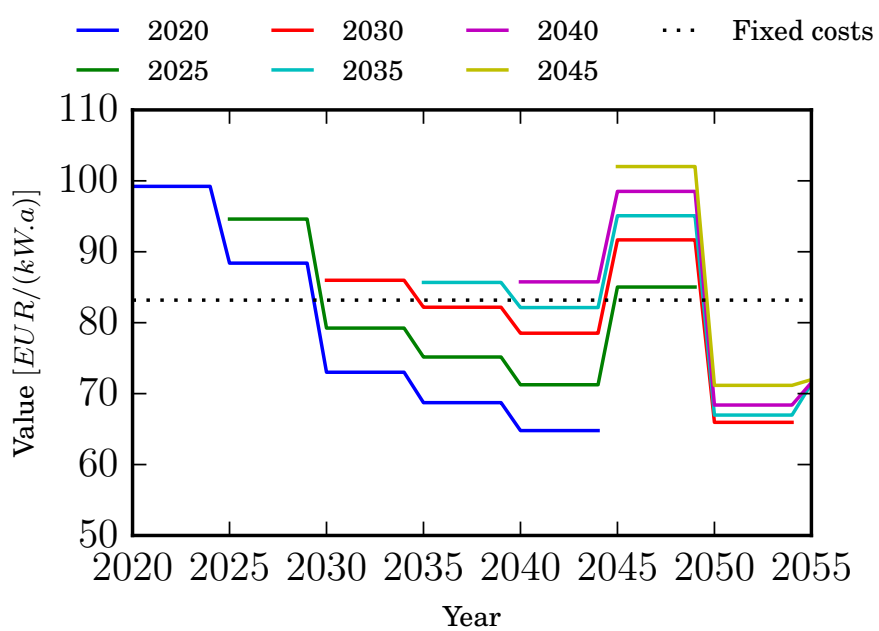

Fig. 5: Evolution of the value of all CCGT assets as a function of the time (horizontal axis) and the year the asset becomes operational (different curves) in the PF scenario.

CCGTs becoming operational in 2020. Due to the gradual retirement of older CCGT plants, which are replaced by new, more efficient ones, the CCGTs that became operational in 2020 are gradually being pushed up the merit order. This leads to a strong reduction of the number of operating hours. More importantly, the retirement of older CCGTs reduces the number of operating hours during which these older CCGTs with higher generation costs set the price, i.e., the new CCGTs can obtain a profit. On the other hand, the increasing natural gas and carbon prices increases the spread between the marginal generation cost of older and new plants, and hence the SR profit that can be obtained in these particular hours. However, the first effect is dominant.

The sudden increase in the value of all operational CCGT assets in the period 2045-2050 in the PF scenario is more difficult to comprehend. As can be seen on Fig. 2a, the capacity mix changes considerably in this period: there is a strong reduction in the capacity of non-CCS CCGTs, while new OCGTs become operational. This rersults in a strong increase in the number of hours where the OCGTs are the marginal generators setting the price, hence increasing the SR profits for all CCGT assets. The fact that the OCGT capacity increases so suddenly is related to the ever increasing amount of intermittent renewale energy sources in the system and the opportunity created by the retirement of the considerable amount of CCGT assets that have become operational in 2020.

The above examples reveal the complexity and the information required to make a detailed projection of the evolution of the value of an asset. Relevant information comprises:

- the evolution of fossil fuel prices;

- the evolution of carbon prices;

- the retirement dates of existing capacity;

- the type, timing and amount of newly built capacity;

- the technological progress of different generation technologies;

- the evolution of the electricity demand;

- future policy interactions (e.g., subsidy schemes, accep- tance of CCS).

In optimization models using perfect foresight, all this information is known in advance. In reality however, this information is not readily available at the time of the decision making. Therefore, the decision making of planning models using perfect foresight might not reflect the decision making in reality. A good example of this is the investment in CCGT assets becoming operational in 2030. As shown in Figure 5, during the first years when the plant is operational, projected profits are barely high enough to recover fixed costs. In addition, the SR profits are expected to decrease gradually during the first 10-15 operational years. For these reasons, it can be considered highly unlikely that private companies would have made this investment. In contrast, the model with $\mathrm{PF}$ anticipates the sudden increase in value in the period 20452050. It is this increase in value which is required to make the investment profitable.

2) Myopic foresight: Myopic models, using a limited window of foresight, aim to simulate investment decision making under uncertainty leading to an increasing focus on the short term. As illustrated in Section IV-A, this can lead to a different evolution of the capacity mix. To take a closer look at the investment decision making in myopic models, the projections of SR profits within the window of foresight are analyzed for the first optimization, i.e., the optimization covering the period 2020-2030. To more clearly illustrate the trends in the projected SR profits within the window of foresight, the MF10 scenario is repeated using 10 periods of a single year each. The resulting projected SR profits that can be obtained by investing in SC coal-fired power plants and CCGTs are presented in Figure 6. Recall that in the myopic model, the foresight and hence the projections of SR profits are restricted to the window of foresight. The SR profits that are obtained in the end are also visualized in Fig. 6.

As can be observed, the projections of the SR profits that can be obtained with SC coal-fired power plants are expected to decrease strongly and systematically during the first decade of operation. This is due to multiple reasons. First and foremost, the strongly increasing carbon price within this decade reduces the spread between the generation cost of the coal-fired power plants and the marginal generator setting the electricity price -being CCGTs in the vast majority of the time. Second, this reduction of the spread is amplified by the gradual replacement of old CCGTs by new, more efficient, ones. In the PF scenario, the model anticipates a further decrease in SR profits and decides not to invest in coal-fired non-CCS plants. Regarding the value of CCGTs coming available in 2020, it is mainly the replacement of old CCGTs by more efficient new CCGTs that causes the slight decrease in projected SR profits.

Despite this clear trend of decreasing SR profits for coalfired generation, the model with myopic foresight decides to invest in a significant amount of coal-fired generation. This is due to the fact that, when calculating the value of an asset outside the modeled time horizon (i.e., the salvage value), it is assumed that the value of an asset is distributed equally over each year of its assumed technical life time. Hence, myopic models will invest in generating capacity as long as the discounted short-run profits within the window of foresight 


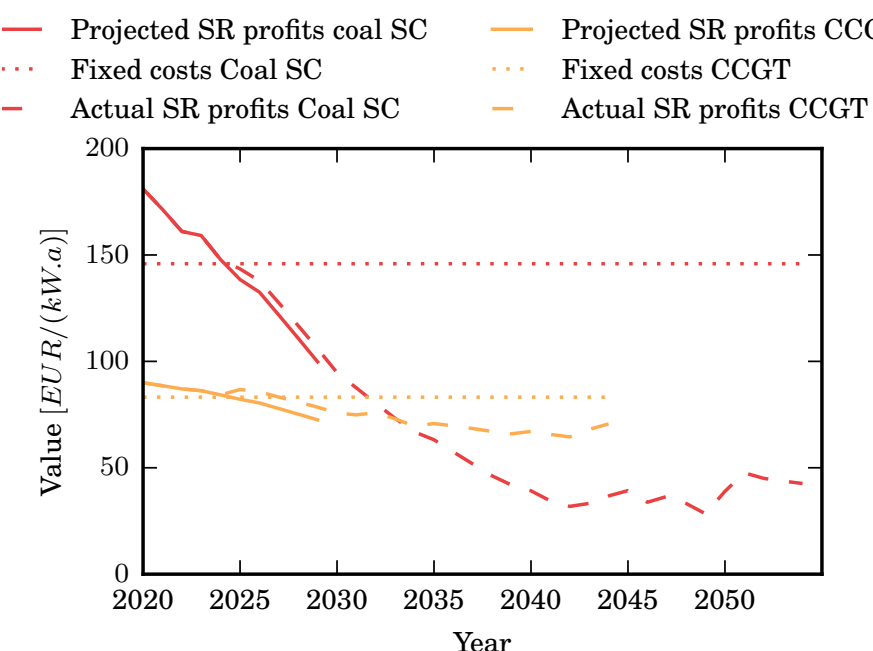

Fig. 6: Evolution of the value of supercritical coal plants and CCGTs as a function of the time (horizontal axis) in the MF10 scenario. The full lines present the projections of the SR profits within the window of foresight at the time the investment decision is made. The dashed lines indicate the actual SR profits after reconsidering investment decisions every 5 years. The dotted lines present the annualized fixed costs.

are at least equal to the discounted annual payments for the fixed costs within this window. Seen from a different perspective, this means that myopic models implicitly extrapolate the discounted average SR profits within the period of the optimization to all years outside the window of foresight, rather than extrapolating the trend in SR profits observed within the window of foresight. For this reason, the investment decision making in myopic optimization models can also not be considered to fully reflect reality.

In addition to this shortcoming, myopic models have some other limitations. First, myopic models consider perfect information for all considered parameters within the window of foresight, while no information is available outside this window. In reality however, certain parameters, e.g., coal prices, can be approximated with reasonable accuracy for a long period, while others, e.g., natural gas prices, are more uncertain. Furthermore, myopic models do not account for the non-linear effects between the value of generating assets and certain parameters (e.g., the non-linear relationship between the value of coal-fired assets and the carbon price around the fuel switching price [19]). Finally, the investment decision making does not endogenously account for the risk related to an investment.

\section{SUMmARY AND CONCLUSIONS}

This paper analyzes the investment decision making in new generating assets in perfect foresight and myopic foresight optimization models. A simplified case study of the evolution of a system inspired by the Belgian electricity system is performed to highlight methodological differences between both models. In this respect, two scenarios are used: one assuming perfect foresight (PF) and a second (MF10) assuming that the window of foresight is restricted to the following 10 years (leading to a sequential decision making process).

The results of this case study show that the modeled foresight can have a significant impact on the outcome of the analysis. In the PF scenario, investments in dispatchable capacity are dominated by CCGTs up to 2045 and later on by CCGTs with post-combustion capture. In contrast, in the MF10 scenario, there is a significant amount of supercritical coal-fired power plants (both with and without carbon capture) entering the mix.

While the myopic approach is suggested by some authors to more realistically simulate the short-term focus of investment decision makers in an uncertain environment, a detailed analysis of the decision making reveals some drawbacks of this approach. Most importantly, these models do not account for the trend observed in terms of profits obtained within the window of foresight. As a result, the investment decision making process in myopic models might also not be reflective of reality.

Further research is required to further improve simulating investment decisions using optimization models. In particular, a combination of a stochastic modeling framework to account for uncertainty with the short-term focus of myopic models could result into an interesting approach.

\section{REFERENCES}

[1] P. Nahmmacher, E. Schmid, and B. Knopf, "Documentation of limes-eu - a long-term electricity system model for europe,' Potsdam Institute of Climate Impact Research (PIK), https://www.pik-potsdam.de/members/ paulnah/limes-eu-documentation-2014.pdf.

[2] I. Keppo and M. Strubegger, "Short term decisions for long term problems the effect of foresight on model based energy systems analysis," Energy, vol. 35, no. 5, pp. 2033 - 2042, 2010. [Online]. Available: http://www.sciencedirect.com/science/article/ pii/S0360544210000216

[3] S. Babrowski, T. Heffels, P. Jochem, and W. Fichtner, "Reducing computing time of energy system models by a myopic approach," Energy Systems, vol. 5, no. 1, pp. 65-83, 2013. [Online]. Available: http://dx.doi.org/10.1007/s12667-013-0085-1

[4] M. Babiker, A. Gurgel, S. Paltsev, and J. Reilly, "Forward-looking versus recursive-dynamic modeling in climate policy analysis: A comparison," Economic Modelling, vol. 26, no. 6, pp. 1341 - 1354, 2009. [Online]. Available: http://www.sciencedirect.com/science/article/ pii/S0264999309001035

[5] F. Hedenus, D. Johansson, and K. Lindgren, "A Critical Assessment of Energy-economy-climate Models for Policy Analysis," Journal of Applied Economics and Business Research, pp. 118-132, 2013.

[6] L. de Vries and P. Heijnen, "The impact of electricity market design upon investment under uncertainty: The effectiveness of capacity mechanisms," Utilities Policy, vol. 16, no. 3, pp. 215 - 227, 2008, capacity Mechanisms in Imperfect Electricity Markets. [Online]. Available: http://www.sciencedirect.com/science/article/pii/S0957178708000027

[7] M. Hasani and S. H. Hosseini, "Dynamic assessment of capacity investment in electricity market considering complementary capacity mechanisms," Energy, vol. 36, no. 1, pp. 277 - 293, 2011. [Online]. Available: http://www.sciencedirect.com/science/article/pii/ S0360544210006043

[8] K. Poncelet, E. Delarue, D. Six, J. Duerinck, and W. D'haeseleer, "Impact of the level of temporal and operational detail in energy-system planning models," Applied Energy, vol. 162, pp. 631-643, Jan. 2016.

[9] A. Pina, C. A. Silva, and P. Ferrão, "High-resolution modeling framework for planning electricity systems with high penetration of renewables," Applied Energy, vol. 112, no. 0, pp. 215 - 223, 2013.

[10] J. P. Deane, F. Gracceva, A. Chiodi, M. Gargiulo, and B. Ó Gallachir, "Soft-Linking Exercises Between TIMES, Power System Models and Housing Stock Models," in Informing Energy and Climate Policies Using Energy Systems Models, G. Giannakidis, M. Labriet, B. Gallachir, and 
G. Tosato, Eds. Cham: Springer International Publishing, 2015, vol. 30, pp. $315-331$.

[11] R. Loulou, U. Remne, A. Kanudia, A. Lehtila, and G. Goldstein, Documentation for the TIMES model: Part I, ETSAP, April 2005.

[12] R. Loulou, A. Lehtila, A. Kanudia, U. Remne, and G. Goldstein, Documentation for the TIMES model: Part II, ETSAP, April 2005.

[13] K. Poncelet, H. Höschle, A. Virag, E. Delarue, and W. D'haeseleer, "Selection of representative days for investment planning models," kU Leuven, TME Working Paper WP EN2015-10, https://www.mech.kuleuven. be/en/tme/research/energy_environment/Pdf/wpen2015-10b.pdf.

[14] B. Palmintier, "Flexibility in generation planning: Identifying key operating constraints," in Power Systems Computation Conference (PSCC), 2014. IEEE, 2014, pp. 1-7.

[15] K. Poncelet, A. van Stiphout, E. Delarue, W. D'haeseleer, and G. Deconinck, "A clustered unit commitment problem formulation for integration in investment planning models," kU Leuven, TME Working Paper WP EN2014-19, https://www.mech.kuleuven.be/en/tme/research/ energy_environment/Pdf/wp-luc.pdf.

[16] ELIA, "Grid data - Elia," Apr. 2015. [Online]. Available: http: //www.elia.be/en/grid-data

[17] S. Simoes et al., "The JRC-EU-TIMES model - Assessing the long-term role of the SET Plan Energy technologies," JRC's Institute for Energy and Transport, Tech. Rep., 2013.

[18] A. Schröder, F. Kunz, J. Meiss, R. Mendelevitch, and C. von Hischhausen, "Data documentation- current and prospective costs of electricity generation until 2050," dIW Working Paper, https://www.diw.de/documents/publikationen/73/diw_01.c.424566.de/ diw_datadoc_2013-068.pdf.

[19] E. Delarue, K. Voorspools, and W. Dhaeseleer, "Fuel switching in the electricity sector under the eu ets: review and prospective," Journal of Energy Engineering, vol. 134, no. 2, pp. 40-46, 2008. 
APPENDIX A

TECHNOLOGICAL CHARACTERISTICS

\begin{tabular}{|c|c|c|c|c|c|c|c|c|c|c|c|}
\hline \multirow[b]{2}{*}{ Technology } & \multicolumn{4}{|c|}{$C^{I N V}\left[\mathrm{kEUR} / \mathrm{kW} \mathrm{W}_{e}\right]$} & \multicolumn{4}{|c|}{$C^{F O M}\left[\mathrm{EUR} /\left(\mathrm{kW}_{e} \cdot\right.\right.$ year $\left.)\right]$} & \multicolumn{3}{|c|}{ VOM [EUR/MWh] } \\
\hline & 2010 & 2020 & 2030 & 2050 & 2010 & 2020 & 2030 & 2050 & & & LT [y] \\
\hline NUCLEAR GEN2 PWR & - & - & - & - & 43 & 43 & 43 & 43 & 5 & 50 & 7 \\
\hline COAL SC PC CCS & - & 2.45 & 2.21 & 2.02 & - & 43 & 41 & 34 & 20 & 35 & 5 \\
\hline COAL SC & 1.71 & 1.70 & 1.70 & 1.70 & 34 & 34 & 34 & 33 & 6 & 35 & 4 \\
\hline CCGT PC CCS & - & 1.24 & 1.16 & 1.09 & - & 44 & 41 & 39 & 10 & 25 & 3 \\
\hline CCGT & 0.86 & 0.86 & 0.86 & 0.86 & 26 & 21 & 20 & 20 & 4 & 25 & 2 \\
\hline OCGT & 0.57 & 0.57 & 0.57 & 0.568 & 17 & 17 & 17 & 17 & 4 & 15 & 2 \\
\hline Wind ON & 1.60 & 1.38 & 1.27 & 1.19 & 36 & 29 & 27 & 25 & - & 25 & 1 \\
\hline PV ROOF & 3.66 & 1.42 & 1.14 & 0.78 & 55 & 21 & 17 & 12 & - & 30 & 1 \\
\hline
\end{tabular}

TABLE I: Economic characteristics of the considered technologies.

\begin{tabular}{|c|c|c|c|c|c|c|c|c|}
\hline & & & NUCLEAR GEN2 PWR & COAL SC PC CCS & COAL SC & CCGT PC CCS & CCGT & OCGT \\
\hline \multirow{4}{*}{ Efficiency } & \multirow{4}{*}[\%]{} & 2010 & 30 & 28 & 45 & 42 & 58 & 42 \\
\hline & & 2020 & 30 & 31 & 46 & 44 & 60 & 45 \\
\hline & & 2030 & 30 & 36 & 49 & 49 & 62 & 45 \\
\hline & & 2050 & 30 & 40 & 49 & 53 & 64 & 45 \\
\hline Minimum stable operating point & {$\left[\% / P_{n o m}\right]$} & & 80 & 50 & 50 & 50 & 50 & 20 \\
\hline Ramp rate & {$\left[\% P_{n o m} / \mathrm{min}\right]$} & & 0.25 & 0.83 & 0.83 & 0.83 & 0.83 & 10 \\
\hline Minimum up time & [hours] & & 24 & 6 & 6 & 4 & 4 & 1 \\
\hline Minimum down time & [hours] & & 48 & 4 & 4 & 1 & 1 & 1 \\
\hline Availability & {$[\%]$} & & 82 & 85 & 85 & 85 & 85 & 85 \\
\hline Capture rate & [\%] & & - & 88 & - & 88 & - & - \\
\hline
\end{tabular}

TABLE II: Technical characteristics of the considered technologies. 